ponent of a growth factor receptor. On the $\mathrm{Ph}^{1}$ chromosome, the expression of the fused $b c r-a b l$ gene is presumably regulated by the control elements of the bcr gene. Since this chromosomal abnormality features prominently only in CML, which is a neoplastic proliferation of haematopoietic stem cells, it is tempting to speculate that the normal bcr gene is expressed primarily in that cell lineage. If the $b c r$ product proves to be a cell-surface protein, one intriguing possibility would be that $b c r-a b l$ represents a hybrid receptor.

While the function of $b c r-a b l$ is a matter of speculation, there now seems little reason to doubt that its formation by the $9 ; 22$ translocation is a critical step in the development of CML. Thus the work on the $\mathrm{Ph}^{1}$ chromosome, when considered together with the large body of work on myc oncogene translocations in lymphoid tumours, makes a strong case that many of the karyotypic alterations found in neoplastic cells represent the activation of specific cellular oncogenes.

1. Nowell, P.C. \& Hungerford, D.A. J. natn. Cancer Inst. 25, 85 (1960)

2. Rowley, J.D. \& Testa, J.R. Adv. Cancer Res. 36, 103 (1982).

3. de Klein, A. et al. Nature 300, 765 (1982).

4. Heisterkamp, N. et al. Nature 306, 239 (1983).

5. Groffen, J. et al. Cell 36, 93 (1984).

6. Gale, R.P. \& Canaani, E. Proc. natn. Acad. Sci. U.S.A. 81, 5648 (1984)

7. Collins, S., Kabonishi, 1., Miyoshi, I. \& Groudine, M. Science 225, 72 (1984)

8. Konopka, J., Watanabe, S. \& Witte, O. Cell 37, 1035 (1984) 9. Konopka, J., Watanabe, S., Singer, J., Collins, S. \& Witte, O. Proc. natn. Acad. Sci. U.S.A. 82, 1810 (1985).

10. Shtivelman, E., Lifshitz, B., Gale, R. \& Canaani, E. Nature 315,550 (1985).

11. Heisterkamp, N., Stam, K., Groffen, J., de Klein, A. \& Grosveld, G. Nature (in the press).

12. Prywes, R., Hoag, J., Rosenberg, N. \& Baltimore, D. J Virol. 54, $123(1985)$

Jerry M. Adams is in the Walter and Eliza Hall Institute of Medical Research, Royal Melbourne Hospital, Victoria 3050, Australia.

\title{
Neurobiology
}

\section{Orchestration at the synapse}

\section{from Clarke R. Slater}

CHEMICAL transmission between neurones or from neurone to muscle takes place at junctions termed synapses. Structural specializations at these junctions ensure that receptor proteins in the post-synaptic membrane are aligned opposite the sites in the presynaptic membrane where transmitter is released. How this alignment comes about and is maintained is important for understanding the hardware of the nervous system and its development. Recent work from U.J. McMahan and his colleagues on the neuromuscular junction has shown that the basal lamina is important for determining the distribution of synaptic components on both sides of the synapse $e^{1,2}$. In two papers starting on page 571 of this issue, McMahan et al. now show that the synaptic basal lamina contains a component chemically very similar to one that causes clustering of molecules that are essential for the functions of the neuromuscular junction ${ }^{3,4}$

The basal lamina is an extracellular layer of material composed largely of a form of the durable connective tissue protein, collagen. A basal lamina sheath surrounds each skeletal muscle fibre and each motor nerve fibre. At the neuromuscular junction, nerve and muscle share a common layer of basal lamina, which has been known for some time to differ chemically from other basal laminae in that it contains a high concentration of acetylcholinesterase (AChE), the enzyme that breaks down acetylcholine (ACh), the transmitter chemical at the neuromuscular junction.

The idea that the basal lamina might influence the distribution of other synaptic components emerged from a series of experiments in which the cells of the neuromuscular junction were destroyed and then either the nerve or the muscle cell was allowed to grow back within the framework provided by the persisting basal lamina sheaths (see figure). When the regenerating nerve made contact with the original synaptic basal lamina, detectable by its persisting AChE activity, it stopped growing and formed the structural features characterizing transmitter release sites ${ }^{1}$. When the muscle cell made contact with the synaptic basal lamina, a high density of receptors for $\mathrm{ACh}$ formed in its surface membrane at the site of contact ${ }^{2}$. As no cellular components of the original neuromuscular junction persisted to induce the local specialization of the regenerating cells, it seems that this information could only have come from the surviving basal lamina.

Since those experiments were reported, several groups have been trying to identify molecules that might mediate the effect of synaptic basal lamina on the distribution of $\mathrm{ACh}$ receptors. One approach has led

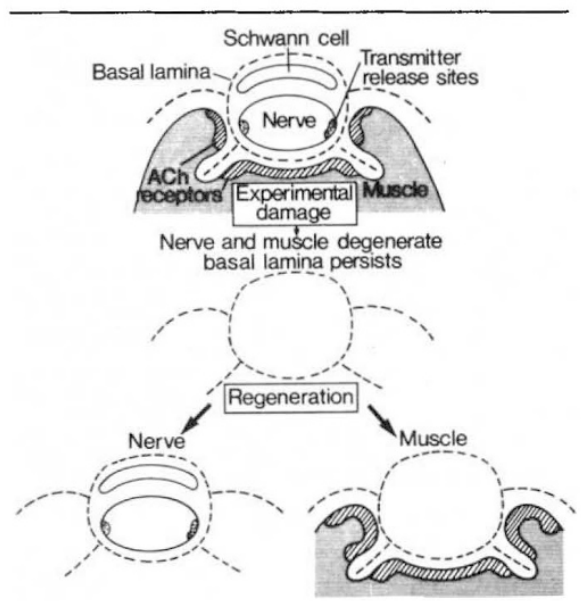

Summary of experiments indicating that the basal lamina regulates the distribution of synaptic components (adapted from ref.2). to the isolation of a variety of tissue extracts that cause the aggregation of $\mathrm{ACh}$ receptors on cultured muscle cells. In other studies, antibodies that specifically label synaptic basal lamina have been raised and used to isolate and characterize the antigens. McMahan et al. have effectively combined these two approaches. Starting with a preparation of basal lamina from the electric organ - essentially a stack of giant neuromuscular junctions - of the fish Torpedo, they obtained a soluble extract that increased the clustering of $\mathrm{ACh}$ receptors on cultured chick muscle cells when present at a concentration of not more than $10^{-10}$ M. An antiserum against this extract bound specifically to the synaptic basal lamina of frog neuromuscular junction and blocked the ability of the extract to induce clusters of $\mathrm{ACH}$ receptors ${ }^{5}$.

In the first of their present papers, McMahan et al. describe monoclonal antibodies, raised against the same extract, that have effects similar to those of their original antiserum ${ }^{3}$. In the second paper $^{4}$, they report that the extract causes the formation of clusters of AChE activity, as well as clusters of $\mathrm{ACh}$ receptors. It is very likely that both clusters occur at the same sites. Because of the specificity and homogeneity of monoclonal antibodies, it can be concluded that a component of the basal lamina at the neuromuscular junction is closely related to, if not identical with, molecules that can induce the clustering of the two most essential molecular components of the synaptic surface of skeletal muscle cells. By studying the effect of these antibodies on the developing neuromuscular junction, it should be possible to define the role that the basal lamina plays in synapse formation.

The antibodies will also be useful in exploring whether the cluster-inducing molecules are present in the central nervous system and how they are produced during synapse formation. Recently, Kelly and his colleagues described a glycoprotein component of the basal lamina of the electric organ ${ }^{6}$. This molecule is also present in the spinal cord of Torpedo, where it is located specifically in the electromotor neurones and is transported in their axons to the periphery. This raises the possibility that, during development, growing motor nerves add components to the basal lamina of the muscle fibre that cause aggregation of the molecules constituting an effective synapse. Experimental tests of such hypotheses should soon be possible.

\footnotetext{
Sanes, J.R., Marshall, L.M. \& McMahan,U.J. J. Cell Biol. 78, 176 (1978)

. Burden, S.J., Sargent, P.B. \& McMahan, U.J. J. Cell Biol. 82, 412 (1979).

3. Fallon, J.R., Nitkin, R.M., Reist, N.E., Wallace, B.G. \& McMahan U.J. Nature 315, 571 (1985).

4. Wallace, B.G. et al. Nature 315, 574 (1985).

5. Godfrey, E.W. et al. J. Cell Biol. 99, 615 (1984)

6. Caroni, P. et al. Nature 314, 441 (1985).
}

Clarke R. Slater is in the Muscular Dystrophy Group, Department of Neurology, University of Newcastle upon Tyne, Newcastle upon Tyne NE4 6BE, UK 